\title{
Analisis Produktivitas Mesin Filling Auto Cup Sealer 1 dengan Metode Overall Equipment Effectiveness pada PT. Prima Kemasindo
}

\author{
Nurhayati $^{*}$, Dene Herwanto ${ }^{2}$, Hamdani ${ }^{3}$ \\ ${ }^{1,2,3}$ Program Studi Teknik Industri, Fakultas Teknik, Universitas Singaperbangsa Karawang \\ *Koresponden email: nurhyt0108@gmail.com
}

Diterima: 29 Agustus 2021

Disetujui: 31 September 2021

\begin{abstract}
The high level of downtime on the ACS 1 filling machine at PT. Prima Kemasindo causes the production process to be not optimal on the machine. The purpose of this study is to identify the maintenance system on the ACS 1 filling machine and measure the productivity level of the ACS 1 filling machine in the period from January to March 2021. This research is applied research using the Overall Equipment Effectiveness (OEE) method. The data used in this study are primary and secondary data obtained from company reports as well as interviews and observations. The results obtained in this study are the Overall Equipment Effectiveness (OEE) value of the ACS 1 filling machine for the period January 98.0\%, February 98.5\%, March 95.2\%, and the average OEE value for the January-March period is $97.2 \%$. Then from the analysis of Six Big Loses, it is known that the highest loss elements are Idling and Mirror Stoppages and Reduced Speed. Based on the results of the fishbone diagram, it is known that the cause of Idling and Mirror Stoppages and Reduced Speed consists of several factors, namely humans, machines, materials, and methods. Several efforts can be made to increase the effectiveness of the use of machines, namely periodic replacement of machine maintenance, periodic operator training, and training on operator self-awareness, the importance of supervision, and operators must always supervise machine parts.
\end{abstract}

Keywords: PT. Prima Kemasindo, productivity, OEE, six big loses, effectiveness

\begin{abstract}
Abstrak
Tingginya tingkat downtime pada mesin filling ACS 1 di PT. Prima Kemasindo menyebabkan tidak optimalnya proses produksi pada mesin tersebut. Tujuan penelitian ini adalah untuk mengidentifikasi sistem perawatan pada mesin filling ACS 1 dan mengukur tingkat produktivitas pada mesin filling ACS 1 dalam periode Januari hingga Maret 2021. Penelitian ini berjenis penelitian terapan dengan menggunakan metode Overall Equipment Effectiveness (OEE). Data yang digunakan pada penelitian ini berupa data primer dan sekunder yang didapatkan dari laporan perusahaan serta wawancara dan observasi. Hasil yang didapatkan pada penelitian ini yaitu nilai Overall Equipment Effectiveness (OEE) mesin filling ACS 1 periode Januari 98,0\%, Februari 98,5\%, Maret 95,2\% dan rata-rata nilai OEE periode Januari-Maret sebesar 97,2\%. Kemudian dari hasil analisis Six Big Loses diketahui elemen kerugian tertinggi yaitu pada Idling and Mirror Stoppages dan Reduced Speed. Berdasarkan hasil diagram fishbone diketahui penyebab terjadinya Idling and Mirror Stoppages dan Reduced Speed terdiri dari beberapa faktor yaitu manusia, mesin, material, dan metode. Beberapa upaya yang dapat dilakukan untuk meningkatkan efektivitas penggunaan mesin yaitu penggantian perawatan mesin secara berkala, pelatihan operator yang dilakukan secara berkala, dan pelatihan tentang kesadaran diri operator pentingnya pengawasan, dan operator harus selalu mengawasi bagian mesin.
\end{abstract}

Kata Kunci: PT. Prima Kemasindo, produktivitas, OEE, six big loses, efektivitas

\section{Pendahuluan}

Saat ini kondisi dunia industri berkembang sangat pesat baik pada bidang barang maupun jasa. Hal ini menyebabkan semakin ketatnya persaingan pada tiap perusahaan. Selain itu juga perusahaan harus menghadapi permasalahan internal seperti produktivitas baik manusia maupun mesin produksi [1]. Saat perusahaan mampu menerapkan produktivitas yang tinggi, ini akan membantu meningkatkan penjualan. Dengan demikian perusahaan dapat melakukan ekspansi usaha dari hasil meningkatnya penjualan tersebut. [2]. Namun untuk mendapatkan hal tersebut perlunya sistem manufaktur yang baik. Perlunya dilakukan perbaikan secara konsisten dari berbagai aspek salah satunya peralatan produksi. Pada aspek ini perusahaan dapat meningkatkan nilai guna dengan optimal sehingga mampu memperpanjang usia produktif dari alat tersebut [3]. Hal ini bertujuan untuk meningkatkan produktivitasnya. Karena produktivitas yang meningkat 
sangat berperan aktif dalam keberhasilan suatu produksi [4]. Mengevaluasi fasilitas atau peralatan perusahaan adalah salah satu contoh dalam hal peningkatan produktivitas perusahaan. Untuk mencapai hal tersebut perlu diadakan suatu mekanisme yang mampu memaksimalkan efektivitas dan efisiensi mesin pada kegiatan produksi. Hal ini karena kedua hal tersebut adalah faktor utama suatu perusahaan selain kualitasnya. Melalui efektivitas dan efisiensi yang optimal dinilai mampu meningkatkan kekuatan perusahaan dalam pasar persaingan [5]. Agar perusahaan mampu mencapai kelancaran dalam proses produksi, perlunya dukungan dari banyak aspek seperti perawatan dan ketersediaan mesin di dalam sistem produksi [6]. Banyak metode yang dapat digunakan untuk mengevaluasi hal tersebut salah satunya Overall Equipment Effectiveness (OEE). Metode OEE adalah bagian Total Productive Maintenance (TPM) yang digunakan untuk memastikan mesin pada kondisi yang baik dengan menghapus enam kerugian besar six big losses mesin [7] [8]. Metode OEE adalah suatu hasil dalam penerapan TPM [9].

PT. Prima Kemasindo merupakan salah satu perusahaan manufaktur yang memproduksi minuman kemasan dan memiliki 9 jenis produk minuman dengan beberapa kategori produk yang berbasis nata, cincau, bolo-bolo, dan minuman rasa buah. Dalam produksinya PT. Prima kemasindo menggunakan berbagai jenis mesin salah satunya mesin filling yang berjenis Auto Cup Sealer (ACS). Dalam penggunaannya mesin filling ACS 1 mengalami tingkat downtime yang tinggi. Terdapat beberapa kemungkinan yang menyebabkan terjadinya hal tersebut, seperti minimnya perawatan atau maintenance, salah pengoperasian, dan lainnya. Oleh karena itu, penelitian ini bertujuan untuk mengidentifikasi sistem perawatan pada mesin filling ACS 1. Selain itu juga untuk mengukur tingkat produktivitas pada mesin filling ACS 1 dalam periode Januari hingga Maret 2021. Metode OEE diterapkan untuk mengidentifikasi sistem perawatan dan mengukur tingkat produktivitas pada mesin filling ACS 1. Metode OEE dapat dijadikan sebagai indikator tingkat produktivitas yang didasarkan pada tiga faktor diantaranya availability, performance efficiency, dan quality rate [10] [11].

Adapun beberapa penelitian terdahulu yang dijadikan sebagai acuan diantaranya penelitian yang dilakukan [12]. Metode OEE diterapkan untuk mengevaluasi efektivitas pada mesin VD-02. Serta mengusulkan tindakan perbaikan yang dapat dilakukan. Penelitian yang dilakukan [13] OEE diterapkan pada mesin Roughing Stand untuk mengetahui prioritas potensi kegagalan berdasarkan urutan nilai Risk Priority Number (RPN). Kemudian dilakukan analisis usulan untuk memaksimalkan kinerja mesin. Penelitian yang dilakukan [14] OEE digunakan untuk mengukur availability, performance of rate, dan effectiveness. Untuk kemudian dilakukan usulan perbaikan berdasarkan hasil pengukuran tersebut. Penelitian yang dilakukan [15] OEE digunakan untuk mengidentifikasi komponen kritis dan menentukan prioritas perawatan berdasarkan nilai Risk Priority Number (RPN). Penelitian yang dilakukan [16] OEE digunakan untuk melakukan perbandingan efektivitas mesin dengan periode sebelumnya. Hasilnya adalah terjadi peningkatan nilai OEE.

\section{Metode Penelitian}

Adapun metode pada penelitian ini adalah digambarkan menggunakan diagram alir (Flow Chart) seperti pada Gambar 1.

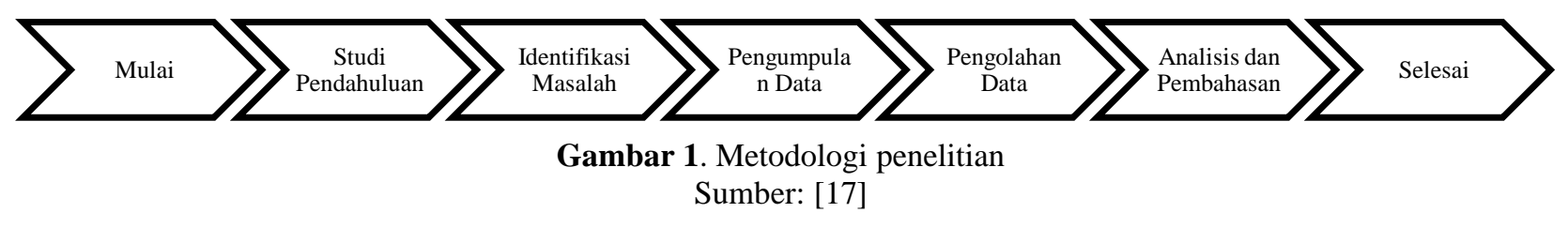

\section{Prosedur}

a. Mulai, pada tahapan ini adalah penandaan sejak dimulainya penelitian ini.

b. Studi pendahuluan yaitu dimaksudkan untuk mencari informasi yang berkaitan dengan penelitian seperti studi literatur dan studi lapangan untuk mempelajari korelasi antara teori dan keadaan lapangan.

c. Identifikasi Masalah, yaitu mengidentifikasikan dan merumuskan permasalahan yang terjadi pada objek penelitian, yaitu berupa terjadinya downtime pada mesin filling ACS 1.

d. Pengumpulan Data, berupa data primer juga data sekunder. Data primer yaitu berupa penyebab terjadinya downtime yang didapatkan dari hasil pengamatan. Sedangkan data sekunder yaitu berupa data downtime mesin filling ACS 1 dan output yang dihasilkan. Data sekunder ini didapatkan dari laporan perusahaan selama periode Januari-Maret 2021. 
e. Pengolahan Data, pada tahap ini dilakukan dengan menggunakan metode OEE). Tahapan perhitungan OEE yaitu dimulai dari mengukur nilai Available rate, Performance, dan Quality rate hingga akhirnya diukur nilai OEE mesin filling ACS 1.

f. Analisis dan Pembahasan, yaitu untuk menganalisis hasil yang didapatkan pada tahap pengolahan data. Dilakukan dengan menggunakan analisis Six Big Loses untuk mengidentifikasi faktor kerugian dan diagram fishbone yang digunakan untuk mengidentifikasi penyebab terjadinya kegagalan tersebut.

g. Selesai, yaitu penandaan selesainya penelitian

\section{Hasil dan Pembahasan}

Data yang digunakan pada penelitian ini adalah berupa output yang dihasilkan oleh mesin filling ACS 1 selama periode Januari-Maret 2021. Data ini akan digunakan dalam proses pengukuran OEE dan analisis Six Big Loses. Data output mesin filling ACS 1 selama periode Januari-Maret 2021 terlihat pada Tabel 1.

Tabel 1. Rekapitulasi Output mesin filling ACS 1 bulan Januari

\begin{tabular}{clcc}
\hline \multirow{2}{*}{ No. Nama Produk } & \multicolumn{2}{c}{ Output } \\
\cline { 3 - 4 } & \multicolumn{1}{c}{ ACS 1 } & ACS 2 \\
\hline 1. Degan Kotak SK 150 ml & 56.168 & 122.466 \\
2. & Blezz Mangga Madu $170 \mathrm{ml}$ & 55.841 & 0 \\
3. & Boss Mangga Madu $150 \mathrm{ml}$ & 2.904 & 0 \\
4. & Boss Coco Sari Kelapa Jumbo $150 \mathrm{ml}$ & 5.985 & 0 \\
5. Boss Coco Es Teller Jumbo 150 ml & 4.938 & 0 \\
6. & KM ORI 170 ml & 9.241 & 0 \\
7. Boss Mangga Madu 170 ml & 14.743 & 141.341 \\
\hline \multicolumn{2}{c}{ Total Output (Karton) } & 149.820 & 3.392 .184 \\
\hline
\end{tabular}

Sumber: PT. Prima Kemasindo (2021)

Tabel 2. Rekapitulasi Output mesin filling ACS 1 bulan Februari

\begin{tabular}{clcc}
\hline \multirow{2}{*}{ No. Nama Produk } & \multicolumn{2}{c}{ Output } \\
\cline { 3 - 4 } 1. & Degan Kotak SK 150 ml & 66.728 & ACS 2 \\
2. & Blezz Mangga Madu 170 ml & 15.123 & 64.457 \\
3. & Boss Mangga Madu 170 ml & 23.820 & 4.309 \\
4. & Boss Coco Sari Kelapa Jumbo 150 ml & 0 & 4.395 \\
5. & Marico Kelapa Muda Original 170 ml & 0 & 12.804 \\
6. & Marico Kelapa Muda Jeruk 170 ml & 0 & 8.445 \\
7. & Boss Coco Es Teller Jumbo 150 ml & 0 & 13.449 \\
8. & Gulas Slim 170 ml & 4.711 & 6.473 \\
9. Piko Rasa Cincau 150 ml & 0 & 0 \\
\hline \multicolumn{2}{c}{ Total Output (Karton) } & 110.382 & 0 \\
\hline
\end{tabular}

Sumber: PT. Prima Kemasindo (2021)

Tabel 3. Rekapitulasi Output mesin filling ACS 1 bulan Maret

\begin{tabular}{clcc}
\hline \multirow{2}{*}{ No. Nama Produk } & \multicolumn{2}{c}{ Output } \\
\cline { 3 - 4 } 1. & Degan Kotak SK 150 ml & 76.659 & ACS 2 \\
2. & Blezz Mangga Madu 170 ml & 29.714 & 65.229 \\
3. & Boss Mangga Madu 170 ml & 29.911 & 4.057 \\
4. & Boss Coco Sari Kelapa Jumbo 150 ml & 4.755 & 1.284 \\
5. & Marico Kelapa Muda Original 170 ml & 421 & 8.951 \\
6. & Marico Kelapa Muda Jeruk 170 ml & 0 & 13.225 \\
7. & Boss Coco Es Teller Jumbo 150 ml & 0 & 8.712 \\
8. & Gulas Slim 170 ml & 15.315 & 17.201 \\
9. Piko Rasa Cincau 150 ml & 4.310 & 0 \\
\hline \multicolumn{2}{c}{ Total Output (Karton) } & 161.085 & 0 \\
\hline & Total Output (Pcs) & 3.866 .040 & 118.659 \\
\hline
\end{tabular}

Sumber: PT. Prima Kemasindo (2021) 
Selain dari data output yang dihasilkan oleh mesin filling ACS 1, digunakan juga data downtime pada mesin filling ACS 1 periode Januari-Maret 2021. Adapun data rekapitulasi downtime periode Januari-Maret 2021 yaitu seperti pada Tabel 4.

Tabel 4. Rekapitulasi Downtime mesin filling ACS 1 Januari-Maret 2021

\begin{tabular}{cccccc}
\hline \multirow{2}{*}{ No. } & \multirow{2}{*}{ Bulan } & \multicolumn{2}{c}{ ACS 1 } & \multicolumn{2}{c}{ ACS 2 } \\
\cline { 3 - 6 } & & Terencana (jam) & $\begin{array}{c}\text { Tidak Terencana } \\
\text { (jam) }\end{array}$ & $\begin{array}{c}\text { Terencana } \\
\text { (jam) }\end{array}$ & $\begin{array}{c}\text { Tidak Terencana } \\
\text { (jam) }\end{array}$ \\
\hline 1. & Januari & 37,70 & 7,32 & 36,85 & 10,30 \\
2. & Februari & 9,88 & 13,10 & 11,53 & 25,15 \\
3. & Maret & 15,21 & 16,98 & 13,21 & 16,55 \\
\hline
\end{tabular}

Sumber: PT. Prima Kemasindo (2021)

Untuk mengukur Overall Equipment Effectiveness (OEE) perlu dilakukan dalam beberapa tahap. Dimulai dari pengukuran tingkat ketersediaan (Available Rate), Tingkat Performa (Performance Rate), dan Tingkat Kualitas (Quality Rate). Berikut ini adalah hasil pengukuran OEE pada mesin filling ACS 1 seperti di bawah ini:

1. Menghitung Available Rate

Terdapat beberapa elemen dalam pengukuran Available Rate.

a. Menghitung nilai Available time Available $_{1}=$ jam kerja $x$ banyak shift $x$ Jumlah hari kerja

b. Menghitung nilai Planned downtime

Planned downtime $=1$ minggu $x$ jumlah jam perawatan

c. Menghitung nilai Loading time

Loading time $=$ Available time - Planned downtime

d. Menghitung Downtime

Downtime $=$ Waktu Breakdwon + Waktu Setup

e. Menghitung Operation time

Operation Time $=$ Loading Time - Downtime

f. Menghitung Nilai Availability Rate

Availability Rate $=\frac{\text { Operating Time }}{\text { Loading time }} \times 100 \%$

Berikut ini adalah hasil perhitungan tingkat ketersediaan (Available Rate) mesin filling ACS 1 seperti pada Tabel 5.

Tabel 5. Hasil Available Rate Mesin FIlling ACS 1

\begin{tabular}{cccccccc}
\hline \multirow{2}{*}{ No. } & Periode & $\begin{array}{c}\text { Available } \\
\text { time }\end{array}$ & $\begin{array}{c}\text { Planned } \\
\text { Downtime }\end{array}$ & $\begin{array}{c}\text { Loading } \\
\text { Time }\end{array}$ & Downtime & $\begin{array}{c}\text { Operation } \\
\text { Time }\end{array}$ & $\begin{array}{c}\text { Availability } \\
\text { Rate }\end{array}$ \\
\hline 1. & Januari & 420 & 37,70 & 382,30 & 7,32 & 374,98 & $98 \%$ \\
2. & Februari & 420 & 9,88 & 410,12 & 5,65 & 404,47 & $99 \%$ \\
3. & Maret & 420 & 15,21 & 404,79 & 16,98 & 387,81 & $96 \%$ \\
\hline
\end{tabular}

Sumber: Hasil pengolahan data (2021)

2. Menghitung Performance Rate

Dalam penentuan tingkat kualitas (Quality Rate) perlu diukur terlebih dahulu waktu siklus ideal.

Berikut ini adalah tahapan dalam pengukuran Quality Rate pada Mesin filling ACS 1.

a. Menghitung Ideal Cycle Time

$$
\text { Ideal Cycle Time }=\frac{\text { Available Time }}{\text { Jumlah produk }(p c s)} \times 100 \%
$$

b. Menghitung Performance Rate

$$
\text { Performance Rate }=\frac{\text { Total Produk }}{\text { Available Time } x \text { Ideal Cycle Time }} \times 100 \%
$$

Berdasarkan persamaan di atas, kemudian dihitung Quality Rate Mesin filling ACS 1 pada periode Januari-Maret 2021. Adapun hasil perhitungan Quality Rate pada Mesin Filling ACS 1 yaitu seperti pada Tabel 6. 
Tabel 6. Hasil Performance Rate Mesin FIlling ACS 1

\begin{tabular}{ccccc}
\hline No. & Periode & Operation Time (jam) & Ideal Cycle Time (jam) & Performance Rate $(\%)$ \\
\hline 1. & Januari & 374,98 & 0,0001 & $100 \%$ \\
2. & Februari & 404,47 & 0,0002 & $99,92 \%$ \\
3. & Maret & 387,81 & 0,0001 & $100 \%$ \\
\hline
\end{tabular}

Sumber: Hasil pengolahan data (2021)

3. Menghitung Quality Rate

Tahap ketiga dalam pengukuran OEE adalah menghitung tingkat kualitas (Quality Rate). Dalam perhitungan Quality Rate dihitung berdasarkan perbandingan antara produk baik dengan produk cacat dari hasil produksi. Berikut ini adalah persamaan yang digunakan dalam menghitung Quality Rate Mesin filling ACS 1:

$$
\text { Quality Rate }=\frac{\text { Good Product }- \text { Reject Product }}{\text { Good Product }} \times 100 \%
$$

Perhitungan Quality Rate dilakukan pada periode Januari-Maret. Adapun hasil Quality Rate Mesin ACS 1 periode Januari-Maret seperti pada Tabel 7.

Tabel 7. Hasil Quality Rate Mesin FIlling ACS 1

\begin{tabular}{ccccc}
\hline No. & Periode & Good Product $($ pcs) & Reject Product (pcs) & Quality Rate (\%) \\
\hline 1. & Januari & 3593497 & 2223 & $99,94 \%$ \\
2. & Februari & 2647014 & 2154 & $99,92 \%$ \\
3. & Maret & 3842911 & 23129 & $99,40 \%$ \\
\hline \multicolumn{5}{c}{ Sumber: Hasil pengolahan data (2021) }
\end{tabular}

Setelah didapatkan nilai available rate, performance rate, dan quality rate, selanjutnya adalah dihitung nilai Overall Equipment Effectiveness (OEE). Berikut ini persamaan yang digunakan dalam perhitungan nilai OEE seperti berikut:

OEE $=$ Availability $\times$ Performance $x$ Quality $x 100 \%$ Tabel 8.

Adapun hasil perhitungan nilai OEE mesin filling ACS 1 periode Januari-Maret 2021 seperti pada

Tabel 8. Hasil OEE Mesin FIlling ACS 1

\begin{tabular}{|c|c|c|c|c|c|}
\hline No. & Periode & Availability Rate (\%) & $\begin{array}{c}\text { Performance Rate } \\
(\%)\end{array}$ & Quality Rate (\%) & OEE $(\%)$ \\
\hline 1. & Januari & $98 \%$ & $100,00 \%$ & $99,94 \%$ & $98,0 \%$ \\
\hline 2. & Februari & $99 \%$ & $99,92 \%$ & $99,92 \%$ & $98,5 \%$ \\
\hline 3. & Maret & $96 \%$ & $100,00 \%$ & $99,40 \%$ & $95,2 \%$ \\
\hline \multicolumn{2}{|c|}{ Rata-rata } & $97,50 \%$ & $99,97 \%$ & $99,75 \%$ & $97,2 \%$ \\
\hline
\end{tabular}

Berdasarkan hasil yang didapatkan, rata-rata nilai Overall Equipment Effectiveness (OEE) mesin filling ACS 1 pada periode Januari-Maret 2021 adalah 97,2\%. Tahap selanjutnya dilakukan analisis menggunakan Six Big Loses. Hal ini dilakukan untuk mengidentifikasi faktor penyebab tidak optimalnya proses produksi pada mesin filling ACS 1. Terdapat enam elemen perhitungan pada analisis Six Big Loses yaitu sebagai berikut:

a. Menghitung Breakdown Loss

$$
B L=\frac{\text { Breakdown Time }}{\text { Loading Time }} \times 100 \%
$$

b. Menghitung Setup/Adjusment Losses

$$
S L=\frac{\text { Setup } / \text { Adjusment Losses }}{\text { Loading time }} \times 100 \%
$$

c. Menghitung Idling and Minor Stoppages

$$
I M S=\frac{(\text { Target Produksi }- \text { jumlah produski)cycle time }}{\text { Loading time }} \times 100 \%
$$

d. Menghitung Reduce Speed Losses 


$$
R S=\frac{\text { Opration Time }-(\text { Ideal Cycle Time } \times \text { Total Produk })}{\text { Loading Time }} \times 100 \%
$$

e. Menghitung Defect Losses

$$
D L=\frac{\text { Total Reject } x \text { Ideal Cycle Time }}{\text { Loading time }} \times 100 \%
$$

Berdasarkan persamaan pada tiap elemen diatas didapatkan hasil perhitungan Six Big Loses pada periode Januari-Maret 2021 yaitu seperti pada Tabel 9.

Tabel 9. Hasil nilai Six Big Loses Mesin FIlling ACS 1

\begin{tabular}{ccccccccc}
\hline No. & Periode & $\begin{array}{c}\text { Breakdown } \\
\text { Lose }\end{array}$ & $\begin{array}{c}\text { Setup/Adjusm } \\
\text { ent Lose }\end{array}$ & $\begin{array}{c}\text { Idling and Minor } \\
\text { Stoppages }\end{array}$ & $\begin{array}{c}\text { Reduced } \\
\text { Speed }\end{array}$ & $\begin{array}{c}\text { Defect } \\
\text { Losses }\end{array}$ & $\begin{array}{c}\text { Scrap } \\
\text { Losses }\end{array}$ \\
\hline 1. & Januari & 0,86 & 0,28 & 6,63 & 0,94 & 0,0007 & 0 \\
2. & Februari & 0,43 & 0,40 & 2,54 & 0,93 & 0,0008 & 0 \\
3. & Maret & 1,23 & 0,36 & 3,06 & 0,92 & 0,0062 & 0 \\
\hline \multicolumn{2}{c}{ Rata-rata } & 0,84 & 0,35 & 4,08 & 0,93 & 0,00 & 0,00 \\
\hline
\end{tabular}

Sumber: Hasil pengolahan data (2021)

Untuk tahap selanjutnya adalah dengan mengidentifikasi prioritas dari keenam elemen pada Six Big Loses. Hal ini bertujuan untuk menganalisis secara lebih mendalam terkait faktor yang paling mempengaruhi terjadinya downtime pada mesin filling ACS 1. Oleh karena itu diukur persentase kumulatif downtime pada tiap elemen Six Big Loses. Adapun hasil perhitungan persentase kumulatif tiap elemen Six Big Loses yaitu seperti pada Tabel 10.

Tabel 10. Persen kumulatif Six Big Loses

\begin{tabular}{lccc}
\hline \multicolumn{1}{c}{ Jenis Kategori Downtime } & Quantity Downtime & Persen (\%) & Persentase Kumulatif \\
\hline Idling and Minor Stoppages & 12,23 & $68,75 \%$ & $68,75 \%$ \\
Reduced Speed & 2,78 & $15,63 \%$ & $84,38 \%$ \\
Breakdown Lose & 2,07 & $11,61 \%$ & $95,98 \%$ \\
\hline \multicolumn{1}{c}{ Jenis Kategori Downtime } & Quantity Downtime & Persen (\%) & Persentase Kumulatif \\
\hline Setup/Adjusment Lose & 0,71 & $3,97 \%$ & $99,96 \%$ \\
Defect Losses & 0,0077 & $0,04 \%$ & $100,00 \%$ \\
Scrap Losses & 0 & $0 \%$ & $100 \%$ \\
Jumlah & 17,79 & & \\
\hline
\end{tabular}

Sumber: Hasil pengolahan data (2021)

Dari hasil persentase kumulatif yang terlihat pada Tabel 10, selanjutnya dibuat dalam bentuk diagram pareto. Hal ini untuk mengidentifikasi dan mengetahui elemen six big loses tertinggi untuk kemudian dianalisis lebih lanjut. Gambar 2 adalah hasil diagram Pareto six big loses.

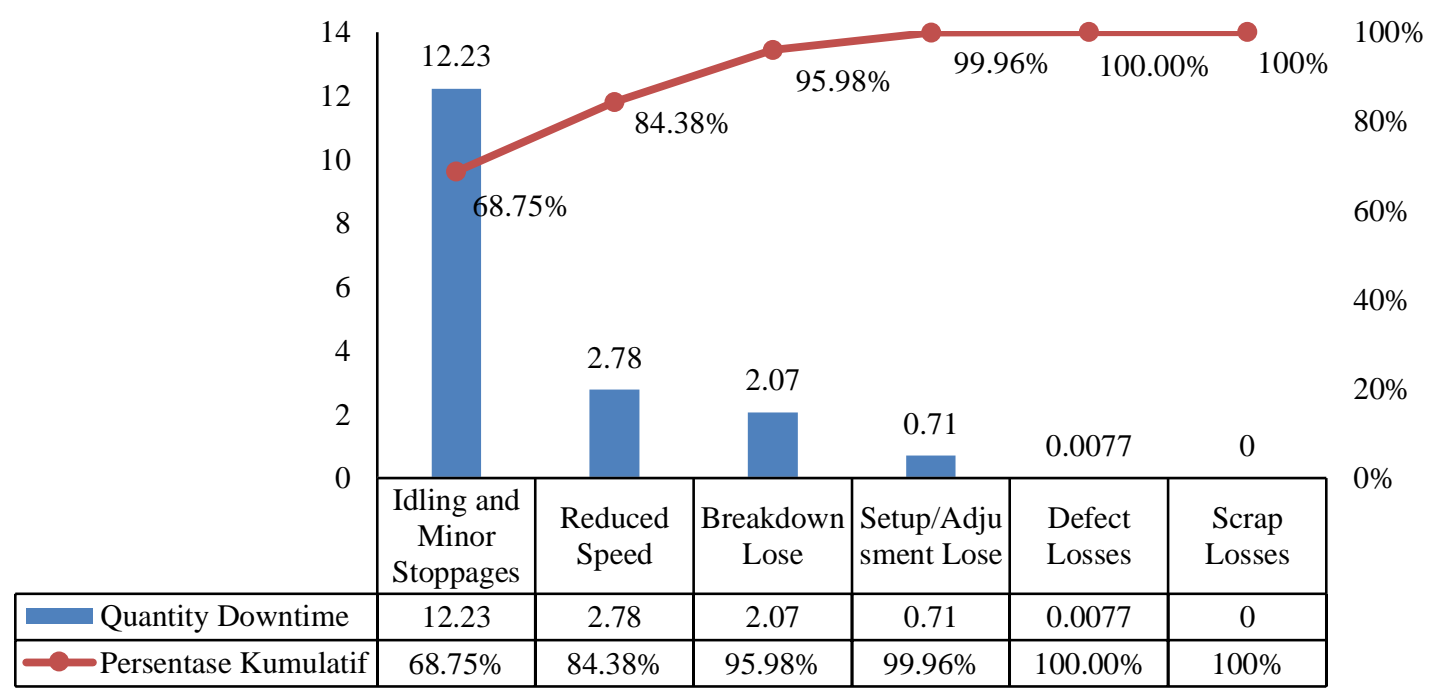

Gambar 2. Diagram Pareto Six Big Loses Mesin Filling ACS 1 Sumber: Hasil pengolahan data (2021) 
Berdasarkan Gambar 2 diagram Pareto, dapat diketahui persentase tertinggi yang paling mempengaruhi terjadinya downtime pada mesin filling ACS 1 yaitu Idling and Mirror Stoppages dan Reduced Speed. Analisis selanjutnya adalah mengidentifikasi penyebab terjadinya kedua kegagalan tersebut. Digunakan diagram sebab-akibat (fishbone diagram) untuk mengidentifikasi penyebab terjadinya kegagalan berdasarkan 4M yaitu Manusia, Mesin, Metode, dan Material. Diagram fishbone untuk kegagalan Idling and Mirror Stoppages dan Reduced Speed seperti pada Gambar 3 dan Gambar 4.

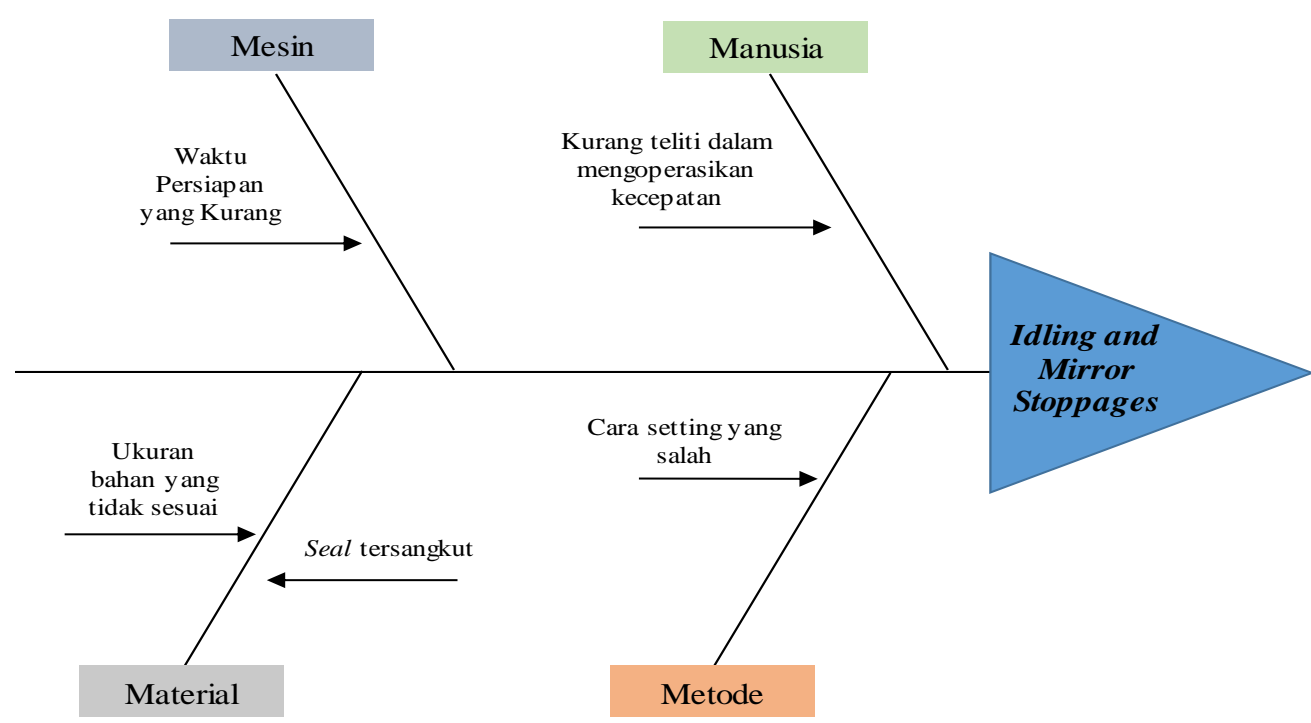

Gambar 3. Hasil diagram fishbone Idling and Mirror Stoppages Sumber: Hasil pengolahan data (2021)

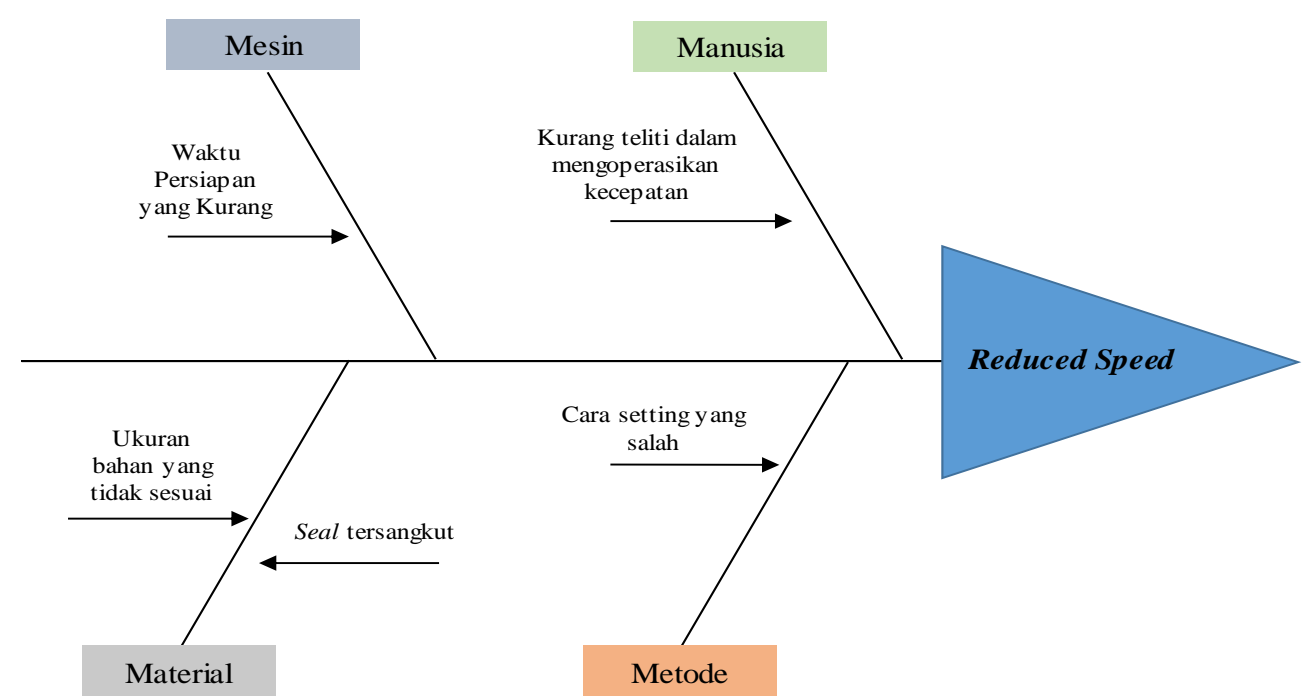

Gambar 4. Hasil diagram fishbone Reduced Speed Sumber: Hasil pengolahan data (2021)

Berdasarkan Gambar 3-4 diagram fishbone, dapat diketahui terdapat beberapa faktor terjadinya Idling and Mirror Stoppages dan Reduced Speed. Faktor-faktor tersebut terdiri dari aspek Manusia, Mesin, Metode, dan Material. Hasil analisis ini diharapkan dapat menjadi indikator dan acuan kedepannya sehingga tidak menyebabkan hal yang sama terjadi sehingga efektivitas penggunaan mesin filling ACS 1 dapat meningkat lebih baik.

\section{Kesimpulan}

Tingkat downtime yang tinggi pada mesin filling ACS 1 menyebabkan produksi yang tidak optimal. Sehingga harus segera dilakukan perbaikan agar hal tersebut tidak kembali terjadi. Berdasarkan hasil analisis Six Big Loses diketahui bahwa elemen kegagalan yang paling tinggi adalah Idling and Mirror 
Stoppages dan Reduced Speed. Beberapa faktor penyebab terjadinya Idling and Mirror Stoppages dan Reduced Speed terdiri dari faktor Manusia, Mesin, Metode, dan Material. Upaya yang perbaikan dilakukan diantaranya yaitu dengan melakukan briefing personil operator untuk meningkatkan kinerja,melakukan pengecekan setiap bagian mesin agar sudah siap sebelum dijalankan, pengecekan bahan baku yang sudah siap sesuai dengan bagian mesin, dan pengecekan operator dalam melakukan tugasnya. Kemudian dengan penggantian perawatan mesin secara berkala, pelatihan operator yang dilakukan secara berkala, dan pelatihan tentang kesadaran diri operator pentingnya pengawasan, dan operator harus selalu mengawasi bagian mesin.

\section{Referensi}

[1] M. Anggraeni, E. Khikmawati dan H. Widiastuti, "Analisis produktivitas mesin press dengan pendekatan overall equipment effectiveness (OEE) Pada PT. Japfa Comfeed Indonesia Lampung," $J$. Rekayasa, Teknik, dan Sains, vol. 1 (2), hal. 132-138, 2017.

[2] N. R. Nurwulan dan D. K. Fikri, "Analisis produktivitas dengan metode OEE dan six big losses: studi kasus di tambang batu bara," J. IKRA-TEKH, vol. 3 (3), hal. 30-35, 2020.

[3] I. Nursanti dan Y. Susanto, "Analisis perhitungan overall equipment effectiveness (OEE) Pada mesin packing untuk meningkatkan nilai availability mesin," J. Ilmiah Teknik Industri, vol. 13 (1), hal. 96$102,2014$.

[4] A. Rahman dan S. Perdana, "Perhitungan produktivitas mesin perfect binding (Yoshino) dengan menggunakan metode overall equipment effectiveness (OEE) pada PT. XYZ," J. String, vol. 3 (1), hal. 16-25, 2018.

[5] P. Suwardiyanto, D. Siregar dan D. Umar, "Analisis perhitungan OEE dan menentukan six big losses pada mesin spot welding tipe X," J. of Industrial and Engineering System (JIES), vol. 1 (1), hal. 1120, 2020.

[6] N. Hairiyah, R. R. Amalia dan R. A. Wijaya, "Analisis total productive maintenance (TPM) pada stasiun kernel crushing plant (KCP) di PT. X," J. Teknologi Pertanian Andalas, vol. 22 (1), hal. 103$110,2019$.

[7] S. Nakajima, Introduction to Total Productive Maintenance, Productivity Press Inc, 1988.

[8] A. Muhsin, "Analisis performansi departemen machinning menggunakan metode overall equipment effectivenes (OEE) (studi kasus pada perusahaan pengecoran logam xyz)," J. OPSI, vol. 9 (1), hal. 16-23, 2016.

[9] A. E. Susetyo, "Analisis overall equipment effectivenes (OEE) untuk menentukan efektifitas mesin sonna web," J. Science Tech, vol. 3 (2), hal. 93-102, 2017.

[10] M. Darsin, “Aplikasi overall equipment effectiveness (OEE) dalam upaya mengatasi tingginya downtime pada stasiun ketel di PG X Jawa Timur," Multitek Indonesia, vol. 13 (2), hal. 95-103, 2020.

[11] V. I. Lestari dan J. A. SZS, "Analisis efektivitas mesin pada stasiun ketel dengan menggunakan metode overall equipment effectiveness (OEE) Di PT. XYZ," Tekmapro:J. of Industrial Eng. and Management, vol. 16 (2), hal. 36-47, 2021.

[12] D. I. Rinawati dan N. C. Dewi, “Analisis penerapan total productive maintenance (TPM) menggunakan overall equipment effectiveness (OEE) dan six big losses pada mesin cavitec di PT. Essentra Surabaya," dalam Prosiding SNATIF, Kudus, 2014.

[13] H. Hasrul, M. J. Shofa dan H. Winarno, "Analisa kinerja mesin roughing stand dengan menggunakan metode overall equipment effectiveness (OEE) dan failure mode effect analysis (FMEA)," J. Intech, vol. 3 (2), hal. 55-60, 2017.

[14] M. M. Hutabarat dan A. Mushin, "Analisis tingkat efektivitas kerja pada mesin auto hanger dengan menggunakan metode overall equipment effectiveness (OEE)," J. OPSI, vol. 3 (1), pp. 56-61, 2020.

[15] R. M. Jannah, Supriyadi dan A. Nalhadi, "Analisis efektivitas pada mesin centrifugal dengan menggunakan metode overall equipment effectiveness (OEE)," dalam Seminar Nasional Riset Terapan, Serang, 2017.

[16] A. Rahmad dan S. Perdana, "Analisis produktivitas mesin percetakan perfect binding dengan metode OEE dan FMEA,” J. Ilmiah Teknik Industri, vol. 7 (1), hal. 34-42, 2019.

[17] A. Gunawan, Kusnadi dan Hamdani, "Analisis produktivitas tenaga kerja dengan metode marvin e. mundel pada CV. Mulia Tata Sejahtera,” J. Serambi Engineering, vol. 6 (3), hal. 2135-2143, 2021. 